\title{
PERCEPÇÃO DOS COORDENADORES DOS CURŞOS DE GRADUAÇÃO DA UFSC SOBRE A MULTIDISCIPLINARIDADE DOS CURSOS QUE COORDENAM
}

\author{
Fernanda de Matos Sanchez Alves* \\ JOSÉ NILSON REINERT**
}

Recebido em: 23/05/2007

Avaliado em: 20/09/07

*Mestre em Administração - CPGA/UFSC. Profa. da Faculdade Capivari - FUCAP.

E-mail: fmsanchez77@yahoo.com.br

**Dr. em Administração de Empresas. Prof. do Curso de Administração - UFMT.

E-mail: icaro.phenix@uol.com.br

Resumo: Este artigo tem por objetivo principal identificar a percepção dos Coordenadores dos cursos de graduação da UFSC quanto à multidisciplinaridade dos cursos que coordenam. $\mathrm{O}$ trabalho se caracterizou como exploratório e descritivo, através de um estudo de caso. Os dados foram coletados por meio de pesquisa documental e questionário. A abordagem utilizada foi qualitativa e quantitativa. Os resultados de pesquisa permitiram concluir que boa parte das respostas dos coordenadores é condizente com a multidisciplinaridade encontrada e descrita na presente pesquisa.

Ainda assim, pode-se constatar que, em alguns cursos, houve discrepâncias entre a multidisciplinaridade encontrada e a multidisciplinaridade percebida pelos coordenadores de cursos de graduação da Universidade Federal de Santa Catarina. Pode-se constatar também que a multidisciplinaridade é um valor percebido como positivo pela maioria dos Coordenadores dos cursos pesquisados.

Palavras-chave: Multidisciplinaridade; Ensino superior; Currículo; Departamento; Coordenadores.

The perception of the Graduate Program Coordinators at UFSC concerning the multidisciplinarity of the programs coordinated by them

Abstract: The main purpose of this article is to identify the perception of the graduate program coordinators of the Federal University of Santa Catarina (UFSC), concerning the multidisciplinarity of the programs coordinated by them. The work was a case study, characterized as exploratory and descriptive. The data were collected through documental research and a questionnaire. The data analysis was qualitative and quantitative. The results of the research allow us to conclude that most of the coordinators' answers match with the multidisciplinarity found and described in this research. Even so, it can be verified that in some programs there were discrepancies between the multidisciplinarity found and the multidisciplinarity noticed by the coordinators of the graduate programs at UFSC. It can also be verified that the multidisciplinarity is a principle seen as positive by most of the coordinators of the researched programs.

Key-words: Multidisciplinarity; Higher education; Curriculum; Department; Coordinators. 


\section{Introdução}

Desde o surgimento das primeiras Universidades, no século XII, estas instituições assumiram e refletiram peculiaridades do contexto social, econômico e político no qual estavam inseridas, com diferentes preocupações e finalidades. Mas, a partir do século XVII, a história destas instituições evoluiu, em grande medida, em função da sua relação com os Estados que se formavam.

Ao longo desse processo verifica-se que se perpetuou a proposta de "grade curricular", que separa a teoria da prática, as disciplinas básicas das profissionalizantes e agrupa, por período determinado, os programas que são ministrados pelo docente. Os programas são dados de forma independente: cada docente planeja sua aula sem, muitas vezes, ter conhecimento do conteúdo ministrado em outras disciplinas.

Apesar da necessidade que vem sendo sentida de uma maior articulação entre disciplinas de um mesmo curso, a realidade do ensino, pelo menos no Brasil, parece estabelecer uma convivência cotidiana com uma organização fragmentada e desarticulada. Os currículos escolares parecem ser constituídos, muitas vezes, por programas estanques e incomunicáveis, que produzem uma formação insuficiente para o enfrentamento das práticas sociais, que exigem algo mais crítico e competente.

Como exemplo, verifica-se que "cada vez mais as disciplinas humanistas, como a sociologia, a filosofia, a psicologia e a teoria econômica estão relegadas a um espaço mais insignificante dentro das novas grades curriculares." (REINERT, 2002, p. 194).

Uma característica ainda encontrada no ensino brasileiro é a predominância da intervenção memorística das escolas, que instituem mérito àqueles que conseguem reter maior número de informações. Inexistem as discussões sobre origem, aplicabilidade e relações de conteúdos, que poderiam promover o enriquecimento cultural.

Para tanto, seria necessário que a Universidade oferecesse uma gama diversificada de disciplinas visando se aproximar mais deste ideal de formação, através de propostas curriculares que apresentassem interação com Departamentos de Ensino diferentes daquele ao qual o curso pressupostamente deveria estar mais intimamente ligado. Vale lembrar que os problemas a serem resolvidos no contexto social demandam, via de regra, conhecimentos multidisciplinares. 
PERCEPÇÃO DOS COORDENADORES DOS CURSOS DE GRADUAÇÃO DA UFSC SOBRE A MULTIDISCIPLINARIDADE DOS CURSOS QUE COORDENAM

\section{Currículo e suas múltiplas faces}

Conforme Berticelli, (1999, p. 161) ao se buscar as origens do currículo, tal como se entende hoje, sob a dupla dimensão do documento escrito e daquilo que é educativo "colocamo-nos, desde já, num emaranhado de filigranas semânticas e histórias que só muito lenta e recentemente se mostram como questão de domínio geral".

Na percepção de Berticelli, currículo é um lugar de representação simbólica, transgressão, jogo de poder multicultural, lugar de inclusões, exclusões e escolhas, produto de uma lógica explícita, muitas vezes e, outras, resultado do que o autor chama de "lógica clandestina", que nem sempre é a expressão da vontade de um sujeito, mas imposição do próprio ato discursivo.

Moreira e Silva (1995, p. 21) esclarecem e ampliam a questão afirmando que "o currículo é uma área contestada, é uma arena política". Por esta razão, é importante conhecer a história da produção do currículo. Segundo os autores:

O currículo não é um elemento inocente e neutro de transmissão desinteressada do conhecimento social. O currículo está implicado em relações de poder, o currículo transmite visões sociais e particulares e interessadas, o currículo produz identidades individuais e sociais particulares. O currículo não é um elemento transcendente e atemporal ele tem uma história, vinculada a formas específicas e contingentes de organização da sociedade e da educação. (p. 22).

É pertinente ressaltar, segundo Berticelli (1999), que o saber educacional, fruto da modernidade, quando a unidade filosófico-teológica se rompe para dar origem às mais diversas ciências particulares, emergentes da técnica, adquire a forma de uma ciência nova, a ciência pedagógica. É neste contexto que surge o currículo, como ordenamento pedagógico. Este conceito de currículo revela a multiplicidade de saberes correlatos de várias ciências.

Na concepção de Saviani (2000), à idéia de currículo soma-se à de ordenação, no sentido de formalização. Dessa forma, o ensino passa a seguir um plano, compreendendo as áreas de estudo a que se dedicaria cada professor e as normas de conduta do estudante. 


\subsection{Disfunções Conceituais na Academia}

Atualmente as "disciplinas" integram os currículos dos cursos de graduação, associadas à idéia de matéria ou conteúdo do ensino, sendo vistas como um componente dos currículos (SAVIANI, 2000, p. 30).

De acordo com estudos feitos por Paviani e Botomé (1993), como consequiência do conhecimento sobre a natureza e do homem, surgiu a necessidade de se demarcar esse conhecimento em áreas, com subdivisões em sub-áreas, cada uma delas recebendo o nome de "disciplina".

A diferenciação dos saberes nos tempos antigos não significava um rompimento. Como preconiza Morin (2000), as ciências não eram vistas como fragmentos do saber. Antes, compunham ligações, como no caso da matemática e da música juntas, da filosofia e da física que formavam a "filosofia natural" etc. A separação das disciplinas científicas da filosofia é um fenômeno que se torna agudo, sobretudo no século XIX, com o advento do positivismo. Conforme Schwartzman (1997, p. 60):

Com o tempo, no entanto, as diferenças foram-se aprofundando, não só pela quantidade de informação e especialização que cada uma requeria como principalmente pela diferença de estilos cognitivos e modelos intelectuais típicos das "duas culturas" do conhecimento. De um lado, uma cultura baseada no uso extenso de várias línguas e na familiaridade com tradições literárias extensas e sutis; do outro, o uso do raciocínio abstrato e dedutivo, a organização sistemática das informações, o uso cada vez maior de instrumentos e a manipulação direta da natureza.

A epistemologia positivista (cuja idéia central concedia ao fato observável a autoridade da "verdade científica") dá lugar às reflexões sobre a fragmentação das ciências. A partir desta distorção das categorias existentes de conhecimento, originou-se a superioridade de algumas ciências, que passaram a ser adotadas como unidades, fazendo das disciplinas (nome dado a categorias de assunto) a base do conteúdo e a razão de ser da escola.

O compartilhamento do conhecimento e sua classificação em "disciplinas", no âmbito da ciência, só acontecem através da maneira como os cientistas trabalham e não porque o próprio conhecimento determine estas categorias; todas possuem sua devida importância e são imprescindíveis para um entendimento global do contexto de produção do conhecimento. 
PERCEPÇÃO DOS COORDENADORES DOS CURSOS DE GRADUAÇÃO DA UFSC SOBRE A MULTIDISCIPLINARIDADE DOS CURSOS QUE COORDENAM

"Tais unidades (programas de ensino) deveriam ser compostas por conhecimentos oriundos de diferentes áreas (ou subáreas) do conhecimento (disciplinas), mas organizadas por critérios oriundos das características da realidade." (PAVIANI; BOTOMÉ, 1993, p. 36).

A fragmentação do conhecimento é fruto da transposição simplista da produção do conhecimento, onde os cientistas categorizam os assuntos de áreas ou disciplinas que estudam, para o contexto do ensino. Esta separação pode ser desastrosa no contexto da preparação de pessoas para usar o conhecimento na solução de problemas.

Desta forma, "programa de ensino" não deve ser a mesma coisa que "disciplina". Conforme Paviani e Botomé (1993), um programa de ensino poderia ser o equivalente unitário, no âmbito da educação, ao que é a disciplina no âmbito da produção do conhecimento.

Na concepção de Paviani e Botomé (1993), há uma confusão entre área de conhecimento, campo de atuação e programa de ensino, onde os conhecimentos práticos oriundos do exercício da ocupação profissional são confundidos como "disciplinas de estudo" e tratados como tal.

Outra relação de grande relevância para Botomé (1996) é a interação entre as necessidades dos cursos de formação e a especialidade dos Departamentos de Ensino como um meio para aumentar a inter e a multidisciplinaridade no trabalho universitário. Assim, se cada matriz curricular, multidisciplinar, representa um tecido coeso, as matérias de cada Departamento, neste trabalho, são as linhas que o tecem.

Morin (2000) adverte que a inteligência que só sabe separar fragmenta o complexo mundo em pedaços, atrofiando as possibilidades de compreensão e reflexão sobre a própria realidade, perdendo-se a oportunidade de um julgamento corretivo e de uma visão de longo prazo sobre a mesma.

Neste caso, mais do que organização em "disciplinas", há uma fragmentação do conhecimento e essa fragmentação acompanha o surgimento das novas profissões oferecidas pela Universidade. Às vezes, parece até que a Universidade perdeu de vista seu papel e sua responsabilidade de trabalhar adequadamente com a produção do conhecimento. Neste sentido, Paviani e Botomé (1993, p. 27) afirmam que:

Várias estruturas da Universidade, como exemplo o Departamento, estão sem função a não ser de exacerbado ativismo político, administrativo, burocrático em torno de "apresentar disciplinas" a alunos e correr atrás de justificativas para manter espaços, poder, status e atividades. 
Numa visão mais ampla, Tobias (1969) apregoa que a Universidade se reduziu a um aglomerado de Faculdades e Institutos Científicos, unidos a um poder central administrativo e os Departamentos, sem o mínimo de contato, são o protótipo encarnado da esfacelação da Universidade. Em vez de corrigir esses desdobramentos, o sistema de educação obedece a eles.

A divisão das ciências só se legitima quando elas não perdem a realidade unitária, de forma a obedecer a um determinado critério que permita que estas parcelas do conhecimento sejam devidamente agregadas ao todo unitário.

\subsection{Currículo globalizante}

O modelo positivista se apresenta como uma justificação da alteração da ordem social. Concebe o mundo, a realidade e o conhecimento como um conjunto de partes justapostas, articuladas entre si, formando um sistema.

Neste sentido, Anastasiou e Alves (2004, p. 51) afirmam que: "A organização tradicional do currículo em grade reflete o modelo da racionalidade científica, que fragmentou a ciência na busca de respostas a questões cada vez mais específicas, constituindo a especialização."

Desta forma, esta fragmentação das ciências gerou a divisão do conhecimento em objetos específicos, como biologia, matemática, geografia, além de outros, que se transformaram nas atuais disciplinas. Isso parece estar bem de acordo com o fracionamento que ocorreu no mundo do trabalho sob a hegemonia do modo de produção capitalista.

Conforme Anastasiou e Alves (2004), os atuais currículos universitários ainda seguem a configuração da "grade" proposta há dois séculos, na qual "o modelo da racionalidade, separa teoria e prática e distingue as disciplinas do básico e do profissionalizante com um conjunto de requisitos, pré-requisitos e outros, com a configuração de coleção". Pior ainda é a verificação da tendência a grades monodisciplinares.

Neste modelo, pretensamente racional, algumas disciplinas são concebidas como mais e outras como menos importantes, formando uma hierarquia. Marcada pelo positivismo, a ciência organiza o conhecimento por áreas e disciplinas que, justapostas e unidas entre si, formam o sistema educacional.

A disciplina apresenta-se como uma forma específica de tratar os conteúdos do conhecimento, a ciência e a realidade, própria da concepção de 
PERCEPÇÃO DOS COORDENADORES DOS CURSOS DE GRADUAÇÃO DA UFSC SOBRE A MULTIDISCIPLINARIDADE DOS CURSOS QUE COORDENAM

mundo positivista e adequada ao modo de produzir a vida na sociedade capitalista. Na prática, tem havido uma divisão em partes cada vez menores, das chamadas disciplinas, permitindo uma fragmentação ainda maior e mais nociva do conhecimento humano.

Em oposição ao paradigma existente, surge uma vertente que propõe a superação da fragmentação e desarticulação das disciplinas através dos três graus existentes de relações disciplinares.

Defendidas por alguns autores como Piaget, Morin e Nicolescu, a multidisciplinaridade, a interdisciplinaridade e a transdisciplinaridade aparecem como propostas para "reformar o pensamento". De acordo com Morin (2000, p. 20) "A reforma do pensamento é que permitiria o pleno emprego da inteligência para responder a esses desafios e permitiria a ligação de duas culturas dissociadas", a cultura científica e a cultura humanista.

A superação da divisão entre teoria e prática e dos saberes técnicos e humanistas se torna necessária neste processo e pode ser tomada como uma possibilidade de quebrar a rigidez dos compartimentos em que se encontram isoladas as disciplinas dos currículos escolares. Para isso, faz-se necessário identificar, conceitualmente, as diferenças entre multidisciplinaridade, interdisciplinaridade e transdisciplinaridade, até mesmo pelo fato de cada uma delas englobar conceitos e referenciais diferentes.

\section{Multidisciplinaridade}

A origem da multidisciplinaridade se encontra na idéia de que o conhecimento pode ser dividido em partes (disciplinas), resultado da visão cartesiana e depois cientificista, na qual a disciplina é um tipo de saber específico e possui um objeto determinado e reconhecido, bem como conhecimentos e saberes relativos a este objeto e métodos próprios. Constitui-se, então, a partir de uma determinada subdivisão de um domínio específico do conhecimento.

De acordo com Morin, a multidisciplinaridade é a justaposição de disciplinas diversas, às vezes sem relação aparente entre elas, ou seja, é o estudo de um objeto sob diversos ângulos, mas sem pressupor um acordo ou um rompimento de fronteiras entre as disciplinas.

A multidisciplinaridade foi considerada importante para acabar com um ensino extremamente especializado, concentrado em uma única disci- 
plina. Sob a ótica de Morin (2000, p. 113) "o grande problema é encontrar a difícil via da interarticulação entre as ciências, que têm, cada uma delas, não apenas sua linguagem própria, mas também conceitos fundamentais que não podem ser transferidos de uma linguagem à outra."

Morin acredita que a história das ciências não se restringe apenas à construção e proliferação das disciplinas, mas de suas interligações e aglutinações que formarão novas disciplinas (disciplinas híbridas) através do intercâmbio mútuo e integração recíproca entre várias ciências. Esta cooperação tem como resultado um enriquecimento recíproco.

A idéia de rede, ou de comunicação entre os campos disciplinares, reforça a tendência do conceito emergente de interdisciplinaridade e transdisciplinaridade. Para Nicolescu (2001), "a disciplinaridade, a multidisciplinaridade, a interdisciplinaridade e a transdisciplinaridade são como quatro flechas lançadas de um único arco: o conhecimento".

Assim, a multidisciplinaridade ocorre quando "a solução de um problema torna necessário obter informação de duas ou mais ciências ou setores do conhecimento sem que as disciplinas envolvidas no processo sejam elas mesmas modificadas ou enriquecidas". Por outro lado, o termo interdisciplinaridade deve ser reservado para designar "o nível em que a interação entre várias disciplinas ou setores heterogêneos de uma mesma ciência conduz a interações reais, a uma certa reciprocidade no intercâmbio, levando a um enriquecimento mútuo". Por último, mas não menos importante, há transdisciplinaridade onde o conceito envolve "não só as interações ou reciprocidade entre projetos especializados de pesquisa, mas a colocação dessas relações dentro de um sistema total, sem quaisquer limites rígidos entre as disciplinas".

Uma das questões que Nicolescu e Morin colocam para discussão é a das diferenças de fundo entre os conceitos de disciplinaridade, multidisciplinaridade, interdisciplinaridade e transdiciplinaridade. É preciso identificar, conceitualmente, as diferenças entre eles. A idéia de integração e de totalidade, que aparentemente perpassa estes conceitos, tem referenciais teórico-filosóficos diferentes, antagônicos, mas complementares.

Segundo Nicolescu (2001, p. 25), "a transdisciplinaridade é radicalmente distinta da multidisciplinaridade e da interdisciplinaridade porque sua meta, a compreensão do mundo presente, não pode ser alcançada dentro do quadro de referência da pesquisa disciplinar." 
PERCEPÇÃO DOS COORDENADORES DOS CURSOS DE GRADUAÇÃO DA UFSC SOBRE A MULTIDISCIPLINARIDADE DOS CURSOS QUE COORDENAM

\section{Metodologia}

A presente pesquisa é de natureza teórico-empírica: os itens propostos foram trabalhados a partir da fundamentação teórica, levantados através de livros e artigos e relacionados com a realidade encontrada nos cursos de graduação da UFSC. Ela se classifica como estudo de caso, pelo fato de ser caracterizada, conforme Gil (1999), pelo estudo profundo e exaustivo de determinado caso, em particular: os cursos de graduação da Universidade Federal de Santa Catarina. A pesquisa se realizou em duas etapas, conforme descrita a seguir.

Num primeiro momento, foi feito um levantamento documental dos currículos atuais de cada curso de graduação da UFSC. Para alcançar o propósito desta pesquisa, foram considerados os currículos do ano de 2004 como atuais, período de início da pesquisa. Estes documentos foram adquiridos através da internet, pelo site da UFSC. Ressalta-se que a busca dos dados principais para análise se deu através dos códigos constantes das "disciplinas" dos currículos, pela inviabilidade de se analisar cada ementa de cada "disciplina". Considerou-se que quanto maior número de Departamentos de Ensino envolvidos o curso tivesse, mais multidisciplinar ele seria.

Desta forma, o aporte quantitativo da pesquisa se deu através da separação das "disciplinas" de acordo com os códigos alfa-numéricos, agrupando aquelas que continham o mesmo código alfa. Com a tabulação manual dos dados, segundo Gil, processo de agrupar e contar os casos que estão nas categorias de análise, identificou-se as unidades envolvidas em cada curso, pressupondo-se que o somatório da carga horária de cada Departamento de Ensino correspondesse à carga de uma única "disciplina", coerentemente com o pensamento de Botomé (1996) sobre o que deveria ser uma disciplina. Assim, cada Departamento de Ensino foi considerado como responsável pela ministração de uma única disciplina, mesmo que o conteúdo cognitivo trabalhado por ele se apresentasse (como geralmente se apresenta) subdividido em diversas "disciplinas".

Denominou-se aqui como Departamento de Ensino Principal aquele que envolvia uma maior carga horária disciplinar no curso, independentemente de ser ou não o de maior importância na formação do estudante, embora se imagine que, pela característica desta mesma carga, deveria sê-lo.

Como decorrência da metodologia aplicada, considerou-se como mais multidisciplinar o curso que apresentasse um maior número de Departa- 
mentos de Ensino envolvido em sua proposta curricular e uma menor concentração de carga de ensino no Departamento de Ensino Principal.

Frente aos resultados empíricos obtidos sobre a multidisciplinaridade dos cursos de graduação da UFSC, optou-se pela investigação da percepção dos coordenadores em relação ao tema desta pesquisa. Para a coleta dos dados primários, elaborou-se um questionário contendo apenas uma pergunta que tinha o intuito de saber o grau que o coordenador atribuía à multidisciplinaridade do curso que ele coordenava, que correspondesse: à realidade percebida por ele e a um ideal a ser alcançado, também de acordo com sua percepção. Para estes dois itens as respostas deveriam estar em números inteiros no intervalo de $1 \mathrm{a} 4$, podendo ser justificadas.

Esta etapa da pesquisa se realizou através de um censo, incluindo todos os coordenadores de todos os cursos de graduação da UFSC, o que se justificou pelo fato da população ser considerada pequena e de fácil acesso. Mesmo assim, apenas 16 coordenadores, de um total de 35, responderam ao questionário.

Para a análise dos dados, partiu-se dos seguintes pressupostos:

- que a multidisciplinaridade é uma realidade desejável, de acordo com as referências teóricas assumidas neste trabalho;

- as atribuições 1 e 2, dadas pelos coordenadores como expressões de suas percepções, foram consideradas como de baixa multidisciplinaridade e 3 e 4 como de alta multidisciplinaridade;

- quando o número de Departamentos de Ensino envolvidos em cada curso foi superior a 9, a multidisciplinaridade do mesmo foi considerada relativamente alta e quando igual ou inferior a 9 foi considerada relativamente baixa. O número 9 foi escolhido como divisor, porque representa o meio entre o maior número de Departamentos de Ensino envolvidos nos cursos de graduação, que ficou entre 18 e 1 .

\section{Resultados}

Aqui estão os resultados encontrados pela pesquisa, desenvolvidos em dois momentos: a) a multidisciplinaridade dos cursos de graduação da UFSC e b) a percepção dos Coordenadores dos cursos sobre a multidisciplinaridade percebida por eles e do ideal a ser alcançado pelo curso que coordenam, ainda na percepção deles. 
PERCEPÇÃO DOS COORDENADORES DOS CURSOS DE GRADUAÇÃO DA UFSC SOBRE A MULTIDISCIPLINARIDADE DOS CURSOS QUE COORDENAM

\subsection{A multidisciplinaridade dos Cursos de Graduação da UFSC}

Os cursos de graduação e pós-graduação estão ligados a diversos Departamentos de Ensino por intermédio de um rol de matérias, cabendo a cada Departamento a alocação dos professores das "disciplinas" por curso a cada semestre.

O Departamento de Ensino, em geral, corresponde ao menor nível de descentralização da gestão dos órgãos centrais, possui algumas competências administrativas específicas e alguma autonomia científica e pedagógica, embora subordinado às estruturas superiores.

O Departamento é tipicamente o nível de estrutura que faz a interface entre a decisão política e de gestão e a atividade científica e pedagógica ou a expressão dos interesses pessoais e coletivos. Em uma boa estrutura departamental, os docentes são, em primeiro lugar, investigadores do conhecimento pertinente àquele Departamento; não são apenas professores de uma ou outra matéria.

Conforme já exposto, a fim de se verificar a multidisciplinaridade, foi analisada a concentração de disciplinas dos Departamentos de Ensino Principal em cada um dos respectivos Cursos de Graduação e o número de Departamentos da UFSC envolvidos no currículo dos mesmos.

Pode-se observar na pesquisa realizada, por exemplo, que o Curso de Farmácia é o que possui a menor concentração no Departamento de Ensino Principal (18,11\%), com 14 Departamentos envolvidos no curso. O Curso de Agronomia também mantém uma baixa concentração de disciplinas no Departamento de Ensino Principal (19,38\%) e possui 18 departamentos envolvidos, o que o torna, com o curso de Farmácia, o mais multidisciplinar em relação aos outros cursos de graduação da UFSC.

Por outro lado, constatou-se que o curso de Direito possui uma maior concentração de disciplinas no Departamento de Ensino Principal $(81,83 \%)$.

O curso de Filosofia é o que possui menor número de Departamentos envolvidos: apenas o Departamento de Ensino Principal, porém, a concentração da carga horária de ensino neste Departamento é de $73,91 \%$, haja vista que, $26,09 \%$ da carga horária do curso é de disciplinas optativas. Desta forma, segundo os critérios adotados nesta pesquisa, o Curso de Direito e o Curso de Filosofia são considerados, os menos multidisciplinares da UFSC.

Os cursos de Farmácia - Análises Clínicas, Farmácia - Tecnologia de Alimentos e Farmácia - Bioquímica possuem um Ciclo Básico comum 
entre eles, sendo que cada habilitação tem formação diferenciada somente no ciclo profissionalizante. Observa-se que, no ciclo básico, poucas são as disciplinas profissionalizantes do Departamento Principal. A grande maioria é de disciplinas que auxiliam o estudante no exercício de sua profissão, como Química, Botânica, Bioquímica e outras.

No caso do curso de Farmácia, as matérias que envolvem outras áreas de conhecimento, mesmo voltadas para o curso de Farmácia, são ministradas por professores dos respectivos Departamentos. Por exemplo, a disciplina de Física para Farmácia é ministrada pelo Departamento de Física, apesar de ser voltada para o curso de Farmácia. O mesmo acontece em outras matérias como Anatomia Aplicada a Farmácia, Histologia Aplicada a Farmácia e Embriologia Aplicada a Farmácia.

A princípio, parece evidente a situação descrita acima ${ }^{1}$, porém ela não ocorre em cursos, como o de Direito, o que justifica sua baixa multidisciplinaridade, nos moldes aqui concebidos. O Curso de Direito é composto, quase totalmente, por matérias do Departamento do Direito. Matérias como Sociologia do Direito, Filosofia do Direito, Ética profissional, Negociação e Mediação e Metodologia da Pesquisa em Direito são ministradas por professores do próprio Departamento de Direito.

Como já mencionado acima, esta situação ocorre com vários cursos de graduação da UFSC, o que vem a ser um dos fatores que acarreta a baixa multidisciplinaridade desses cursos, nos termos aqui concebida, e menor participação e envolvimento dos vários Departamentos da Universidade em cada um de seus cursos.

Cabe ressaltar a variação existente na multidisciplinaridade entre os mesmos cursos com habilitação em licenciatura e bacharelado, como Geografia, Química, Física, Filosofia, Português, Psicologia, Matemática, Italiano, Alemão, Francês, Espanhol, Inglês, Ciências Biológicas e Ciências Sociais. Dentre esses cursos, aqueles com habilitação para licenciatura são mais multidisciplinares e possuem maior número de Departamentos de Ensino envolvidos do que os cursos com habilitação em bacharelado.

Isso ocorre porque os currículos dos cursos com habilitação em licenciatura são mais voltados para a carreira acadêmica, possuindo, desta forma, matérias complementares de vários Departamentos da UFSC, como o de Psicologia e Educação, enquanto que os cursos de bacharelado concentram suas matérias no Departamento de Ensino Principal, o que acarreta

1 Conforme pesquisa realizada em Alves (2006). 
PERCEPÇÃO DOS COORDENADORES DOS CURSOS DE GRADUAÇÃO DA UFSC SOBRE A MULTIDISCIPLINARIDADE DOS CURSOS QUE COORDENAM

um menor número de Departamentos envolvidos no curso e, consequentemente, uma menor multidisciplinaridade.

\subsection{Percepção dos Coordenadores sobre a} multidisciplinaridade dos cursos que coordenam.

Apesar dos questionários terem sido enviados para todos os Coordenadores de Curso, obteve-se apenas a resposta de 16 Coordenadores dos cursos de graduação, a saber: Ciências Contábeis, Ciências Econômicas, Serviço Social, Jornalismo, Filosofia, Geografia, Matemática, Engenharia Controle e Automação, Engenharia Mecânica, Engenharia de Aquicultura, Agronomia, Arquitetura e Urbanismo, Psicologia, Enfermagem, Medicina e Odontologia.

Com o intuito de obter a percepção dos Coordenadores sobre a multidisciplinaridade dos cursos que coordenam, perguntou-se a opinião a respeito da realidade percebida e sobre o ideal a ser alcançado em uma escala de um a quatro, um representando a mais baixa multidisciplinaridade percebida e quatro a mais alta. As respostas estão resumidas no quadro a seguir:

Percepção dos coordenadores sobre a multidisciplinaridade atual dos cursos que coordenam e a multidisciplinaridade ideal.

\begin{tabular}{|l|c|c|c|c|c|c|c|c|}
\hline & \multicolumn{4}{|c|}{ Realidade percebida do curso } & \multicolumn{3}{|c|}{ Ideal a ser alcançado } \\
\hline Multidisciplinaridade & $\mathbf{1}$ & $\mathbf{2}$ & $\mathbf{3}$ & $\mathbf{4}$ & $\mathbf{1}$ & $\mathbf{2}$ & $\mathbf{3}$ & $\mathbf{4}$ \\
\hline No. Coordenadores & $\mathbf{1}$ & $\mathbf{9}$ & 5 & $\mathbf{1}$ & - & 1 & 7 & 8 \\
\hline
\end{tabular}

Fonte: Alves, 2006

Boa parte das respostas do questionário sobre a realidade percebida em relação à multidisciplinaridade foi condizente com a realidade encontrada na presente pesquisa. Percebeu-se que a maioria dos Coordenadores (10) considerou os cursos que coordenavam como de multidisciplinaridade relativamente baixa e julga importante a multidisciplinaridade nos cursos de graduação. Dos 16 respondentes, 15 Coordenadores consideraram 3 e 4 como a multidisciplinaridade ideal. 
Observou-se que Coordenadores de cursos muito multidisciplinares (com 18, 15 e 14 Departamentos de Ensino envolvidos) perceberam estes cursos como pouco multidisciplinares. Além disso, pode-se perceber que os Coordenadores de dois dos três cursos constantes nesta categoria perceberam que a multidisciplinaridade de seus respectivos cursos deveria ser ainda maior, ou seja, aqueles que coordenavam os cursos mais multidisciplinares da UFSC idealizaram para os mesmos uma multidisciplinaridade ainda maior. Nenhum dos respondentes manifestou o desejo de diminuir a multidisciplinaridade de seus respectivos cursos.

No outro extremo, dois Coordenadores de cursos que se encontravam entre os menos multidisciplinares da Universidade perceberam os mesmos como muito muldisciplinares.

Dois outros coordenadores perceberam seus cursos como altamente multidisciplinares e idealizaram também altamente sua multidisciplinaridade. É importante destacar que nenhum dos Coordenadores percebeu a multidisciplinaridade de seus respectivos cursos como excessiva.

Sete Coordenadores de cursos que estão entre os últimos da universidade, em termos de multidisciplinaridade, perceberam os mesmos como pouco multidisciplinares. Mas é muito significativo o fato de que dentre eles, seis idealizaram uma multidisciplinaridade maior para seus respectivos cursos.

O que se pode observar é que a maioria dos respondentes, 11 entre 16 (quase 70\%) percebeu o curso que coordenava em alinhamento com a realidade de sua maior ou menor multidisciplinaridade.

Cinco outros respondentes, no entanto, perceberam a realidade multidisciplinar do curso em discordância com a realidade. Um Coordenador de um curso com apenas 4 Departamentos de Ensino envolvidos na estrutura curricular, situando-se entre os últimos, em termos de multidisciplinaridade, considerou-a boa, embora ainda ache que possa ser melhorada.

Se o número de respondentes for tomado como uma amostra da população de coordenadores de cursos de graduação da UFSC, pode-se dizer que $75 \%$ (12 entre 16 Coordenadores de cursos) idealizaram uma multidisciplinaridade maior que a percebida atualmente, o que representa um dado extremamente significativo, na opinião dos autores.

Quatro Coordenadores tiveram uma percepção idealizada de multidisciplinaridade equivalente à realidade percebida atualmente. É muito importante registrar que nenhum destes Coordenadores teve uma percep- 
PERCEPÇÃO DOS COORDENADORES DOS CURSOS DE GRADUAÇÃO DA UFSC SOBRE A MULTIDISCIPLINARIDADE DOS CURSOS QUE COORDENAM

ção idealizada de multidisciplinaridade inferior à percepção da multidisciplinaridade atual em seus respectivos cursos. Ainda se sobressai a informação de que três dos quatro coordenadores (75\%) que se enquadram nesta categoria coordenam cursos que são altamente multidisciplinares em relação aos demais cursos da UFSC.

\subsection{Considerações de alguns Coordenadores de curso sobre multidisciplinaridade}

Percebe-se que alguns Coordenadores de Curso foram otimistas nas análises dos cursos que coordenavam. O Coordenador de um dos cursos considerou que o mesmo tem caráter multidisciplinar, com abordagem teórica, técnico-histórica, construtiva, experimental, projetual e artísticocultural. O Coordenador de outro curso afirmou que o mesmo se desenvolve através de duas áreas básicas; considerou que a interdisciplinaridade permeia todo o currículo, buscando um equilíbrio dessas duas áreas.

Dentre os questionários respondidos, o Coordenador de um dos cursos, com multidisciplinaridade percebida como 2 e o ideal a ser alcançado como 2, justificou que sua área já é bastante ampla, por isso não há necessidade de se inserir mais matérias. Segundo o Coordenador: "Disciplinas de economia, administração, estatística, matemática, etc, são vitais e já tomam bastante tempo".

Outro Coordenador considerou o curso altamente multidisciplinar em pelo menos duas dimensões, a dimensão prática e a dimensão técnica. Ele julgou importante, no curso de engenharia, os conhecimentos em meio ambiente, administração e legislação.

Ressalta-se a dificuldade encontrada por um Coordenador da área da saúde em tornar o curso mais multidisciplinar, devido à sua estrutura e aos modelos adotados pelos professores do curso. Corroborando este ponto de vista, o Coordenador de outro curso alegou que os alunos são expostos a conhecimentos fragmentados, mas que cabe a eles integrá-los na vida profissional.

Um Coordenador da área de exatas sugeriu uma maior integração entre os Departamentos de Ensino para que efetivamente ocorresse a multidisciplinaridade que, no entendimento dele, não significa apenas várias disciplinas com abordagens diferentes, mas também convergências, divergências, relações e tensões entre essas abordagens. 
Muitos Coordenadores vislumbravam a realidade em que trabalham além da multidisciplinaridade, focando a interdisciplinaridade e a transdisciplinaridade, que se acredita estarem, atualmente, além das fronteiras alcançadas pelos cursos.

\section{Conclusões}

Num primeiro momento, crê-se que uma maior multidisciplinaridade nos Cursos de Graduação da UFSC já mudaria muito a realidade dos mesmos, trocando pelo menos parte do adestramento técnico por uma formação mais generalista, humanista, realista, holística, crítica, complexa e condizente com as reais necessidades dos indivíduos e das sociedades onde os mesmos estão inseridos.

A primeira conclusão importante que se pode tirar deste trabalho é que a multidisciplinaridade tem um valor altamente positivo entre os Coordenadores de Curso de graduação da UFSC. Isso coincide com a concepção dos autores pesquisados, para quem a multidisciplinaridade se contrapõe à visão positivista de construção do conhecimento e formação acadêmica. Rompe com a visão profissional baseada no modelo fordista, pois quando este modelo foi estruturado, atendia a uma realidade, na qual a formação centrada no profissionalismo excessivo centrava-se na especificidade e na delimitação de competências e habilidades em uma determinada área do conhecimento.

Setenta e cinco por cento dos Coordenadores respondentes idealizaram uma multidisciplinaridade superior àquela percebida na realidade atual dos cursos coordenados por eles. Dentre os vinte e cinco por cento não incluídos nesta categoria, nenhum idealizou uma multidisciplinaridade inferior àquela percebida atualmente nos seus respectivos cursos. Destes, setenta e cinco por cento coordenavam cursos que estavam entre os mais multidisciplinares da UFSC.

Esse dado, certamente, aponta para a necessidade de a Universidade desenvolver esforços no sentido de propiciar um caminhar mais célere em direção a cursos que contemplem maior multidisciplinaridade. Para tanto, é preciso que haja uma preparação neste sentido, pois, certamente, há na comunidade acadêmica uma grande divergência, ou quem sabe, um grande desconhecimento, sobre o que de fato seja multidisciplinaridade. 
PERCEPÇÃO DOS COORDENADORES DOS CURSOS DE GRADUAÇÃO DA UFSC SOBRE A MULTIDISCIPLINARIDADE DOS CURSOS QUE COORDENAM

Neste sentido, os dados coletados traduzem um grande esclarecimento. Coordenadores de cursos com alta multidisciplinaridade relativa perceberam os mesmos como pouco multidisciplinares e Coordenadores de cursos com baixa multidisciplinaridade relativa perceberam-nos como muito multidisciplinares. Os dados demonstraram que Coordenadores de cursos altamente multidisciplinares idealizaram uma multidisciplinaridade ainda maior enquanto cursos com baixa multidisciplinaridade consideraram esta realidade suficiente. Nem sempre a multidisciplinaridade percebida coincidiu com a multidisciplinaridade detectada.

Tendo em vista os estudos realizados, ficaram bastante perceptíveis os diferentes níveis de multidisciplinaridade existentes nos cursos de Graduação da Universidade Federal de Santa Catarina. Ressalta-se também, de um modo geral, a consciência por parte dos Coordenadores de Curso da importância da multidisciplinaridade e da troca de conhecimento entre os Departamentos de Ensino, o que poderia estar ocorrendo em maior grau nos cursos de graduação.

Constatou-se a formação humanística, generalista e multidisciplinar, muitas vezes, existe em grau muito pequeno, até mesmo nos cursos considerados nesta pesquisa como os mais multidisciplinares. Em muitos cursos, ainda há uma predominância da visão superespecializada, manifestada pela grande centralização em um único Departamento de Ensino.

A substituição do modelo de grade, com o enfoque predominantemente disciplinar e seqüenciado, por uma nova estrutura mais multidisciplinar, que possibilitasse ao estudante uma maior participação do seu próprio processo de formação, certamente ajudaria muito na apreensão e disseminação efetiva de um conhecimento mais completo e mais adequado à complexidade e à dinamicidade que caracterizam a realidade atual.

\section{REFERÊNCIAS}

ALVES, Fernanda de Matos Sanchez. A multidisciplinaridade nos cursos de graduação da UFSC: um estudo comparativo. 2006. 149 f. Dissertação (Mestrado em Administração) - Programa de Pós-Graduação em Administração, Universidade Federal de Santa Catarina, Florianópolis, 2006.

ANASTASIOU, Lea das Graças Camargo, ALVES, Leonir Pessate. Processos de ensinagem na universidade: pressupostos para as estratégias de trabalho em aula. Joinville: UNIVILLE, 2004. 
BERTICELLI, Ireno Antonio. Currículo: tendências e filosofia. In: COSTA, Marisa Vorraber. O currículo nos limiares do contemporâneo. Rio de janeiro: DP\&A, 1999.

BotomÉ, Sílvio Paulo. Pesquisa alienada e ensino alienante: o equívoco da extensão universitária. Petrópolis: Vozes, 1996.

GIL, Antonio Carlos. Métodos e técnicas de pesquisa social. São Paulo: Atlas, 1999.

MOREIRA, Antonio Flávio; SILVA, Tomaz Tadeu (Orgs.). Currículo, cultura e sociedade. São Paulo: Cortez, 1995.

MORIN, Edgar. A cabeça bem-feita: repensar e reforma, reformar o pensamento. Rio de Janeiro: Bertrand, 2000.

NICOLESCU, Basarab. O manifesto da transdisciplinaridade. São Paulo: Triom, 2001. Coleção Trans.

PAVIANI, Jayme, BOTOMÉ, Sílvio Paulo. Interdisciplinaridade: disfunções conceituais e enganos acadêmicos. Caxias do Sul: EDUCS, 1993.

REINERT, José Nilson. Cursos de graduação em administração: a necessidade de um novo enfoque. In: A GESTÃO universitária em ambiente de mudanças na América do Sul. Blumenau: Nova Letra, 2002.

SAVIANI, Nereide. Saber escolar, currículo e didática: problemas da unidade conteúdo/método no processo pedagógico. São Paulo: Autores Associados, 2000.

SCHWARTZMAN, Simon. A redescoberta da cultura. In: ENSAIOS de cultura. São Paulo: EDUSP, 1997.

TOBIAS, José Antônio. Universidade: humanismo ou técnica. São Paulo: Herder, 1969. 